\title{
PASSADO E NATUREZA NAS NARRATIVAS DE VIAGEM AO BRASIL E AO ORIENTE (SÉCULO XIX)
}

Vera Chacham*

RESUMO:

\author{
Em um século - o XIX - no qual a história é identificada com \\ o tempo linear e cumulativo, as narrativas de viagem ao \\ Brasil e ao Oriente serão pontuadas por imagens da ausência \\ da história. Contudo, o viajante europeu identificará o \\ Brasil com a natureza e o Oriente com o passado. \\ PALAVRAS-CHAVE: Oriente, narrativa de viagens, século XIX, história, \\ Brasil, natureza, cidade.
}

Em Histoire stationnaire et histoire cumulative, Lévi-Strauss argumentava que definimos uma cultura como evolutiva ou estacionária conforme a proximidade ou distância em que se encontra da nossa própria cultura (Cf. Lévi-Strauss, 1990: 42). Esta proposição simples, espécie de emblema relativista, é contudo confirmada a cada viagem empreendida a lugares distantes, pelo menos enquanto não se conhece um pouco melhor a complexa rede de relações que caracteriza toda sociedade. Assim é quando se vai aos Estados Unidos em tempos normais e se esquece dos noticiários apocalípticos da televisão brasileira; assim é quando se caminha à beira de um lago suíço em pleno outono e se descobre a verdade cíclica das estações. Teríamos, nessas ocasiões, uma apreensão do tempo histórico que contrasta com a nossa experiência, pois, estranhamente, os países que regem o mundo tornam-se "quadros da natureza", docemente previsíveis, deliciosamente estacionários, placidamente promissores, enquanto o nosso tempo, repleto de eventos e inconstância, apontaria para um aparente dinamismo histórico.

Não necessariamente a mesma mas algo semelhante seria a perspectiva dos viajantes europeus aqui e alhures, há mais de um século. Do território da História

* Doutora em Letras: Estudos Literários (Área de concentração: Literatura Comparada), 2002. 


\section{EMTESE}

Belo Horizonte, v. 7, p. I-I I 0, dez. 2003

que era a Europa eles partiam para terras que consideravam decadentes ou inertes, que mal haviam começado sua história ou cuja história era puro passado, escombro sobre o qual seria difícil construir algo novo. O Oriente, o Brasil, ainda não haviam encontrado o caminho da história, do progresso.

Em um século em que a história era cada vez mais identificada com o tempo linear e cumulativo, muitas das antigas formas de comparação entre a Europa e "os outros" se resumiam à existência ou inexistência de um progresso histórico. Essa perspectiva temporal global, que fornece uma nova justificativa ao eurocentrismo, não situa da mesma forma, contudo, o Oriente e o Brasil perante o ideal europeu. Nas descrições de cidades como o Cairo ou o Rio de Janeiro, o viajante europeu construirá freqüentemente suas imagens de inércia por meio da identificação da cidade brasileira com a natureza, enquanto a cidade oriental será associada ao passado.

0 que o viajante descreve, contudo, não consiste em pura negatividade, na total inexistência de sinais de progresso. Na verdade, no fim do século XIX, o viajante não se depara com antigas imagens do Oriente e do Brasil, mas com jovens nações engajadas em processos e tentativas de modernização e ocidentalização. Desse modo, é do confronto entre antigos topoi, novos ideais e novas paisagens que surgem identificações inéditas do Brasil com a natureza e novos significados para o espaço do passado encarnado no Oriente.

Essas narrativas estarão marcadas, assim, pela ambigüidade, porque a presença, antes desejada, de reformas nunca é de fato perfeita, detendo-se sempre na aparência ou, ao contrário, atingindo seriamente a imagem que se possuía do lugar. Assim, quando tudo parece indicar uma inclusão dessas alteridades na concepção de tempo histórico idealizado pelos europeus, ocorre, do ponto de vista dos viajantes, um desvio, ou ainda uma sensação de perda. Em certa medida é o que podemos perceber em narrativas de viagens a cidades brasileiras e egípcias na segunda metade do século XIX. A grande diferença está na nova dimensão que o passado adquire para o viajante ocidental e com ele a paisagem oriental. Isto parece permitir, no caso do oriente, um olhar crítico da missão civilizatória, o que, pelo menos até o princípio do século XX, não será a tônica em relação ao Brasil. 
Desde as Lettres Persannes (1721) encontramos imagens da estagnação e inércia orientais, assim como da inexistência de uma perspectiva de futuro. 0 Oriente foi para o viajante europeu, ao longo do século XVIII, lugar de decadência e miséria. Somente quando situado numa perspectiva temporal linear e cumulativa, contudo, é que o Oriente torna-se o lugar do passado, espécie de espelho às avessas do ocidente: o oposto do progresso e possivel campo de conquista.

Contudo, a noção de uma temporalidade linear e irreversível, ao abrir as portas do futuro, abre igualmente a possibilidade da compreensão e da identidade em relação ao passado. A filosofia histórica do romantismo também nasce com a quebra do tempo explicitada pela Revolução Francesa, mas, ao invés de uma atitude otimista em relação ao presente e ao futuro, o romântico foge em direção ao passado (embora escolha muitas vezes a via utópica do futuro). O Oriente, além da fuga exótica, permite ainda uma fuga no tempo, através da experiência sincrônica do passado.

É sobretudo com as viagens de Nerval (1843), de Gautier (1852), de Flaubert (1850) que se desenvolve a idéia e a busca de um Oriente autêntico, histórico, verdadeiro, apropriado a uma verdadeira evasão. 0 "verdadeiro" Oriente que se busca é, em grande parte, o das Mil e uma Noites, uma referência literária que se transforma tranqüilamente em referência histórica, o testemunho de um Oriente ainda intocado pela "civilização" e anterior aos fenômenos de aculturação ocidental.

Os viajantes da segunda metade do século XIX herdam dos românticos as imagens da paisagem oriental "autêntica" e, sobretudo através de descrições da cidade do Cairo, compõem um exotismo profundamente histórico e situado na contracorrente do processo de europeização.

Podemos encontrar a especificidade deste ol har exótico sobre o Oriente no texto que Eça de Queirós escreve a partir de uma viagem de 1869 ao Egito. Em certas partes da sua fragmentada narrativa, a descrição do Cairo possibilita ao autor o contraste mais consciente com a cidade produzida pela racionalidade ocidental, em particular as cidades reformadas nos moldes de Haussmann. Em Eça, a cidade oriental oferece a fuga absoluta do tempo ocidental mas também a sua crítica, ao 


\section{EMTESE}

Belo Horizonte, v. 7, p. I-I I0, dez. 2003

fazer do espaço e da temporalidade orientais uma experiência que, ora nostálgica ora utópica, revela limites e contradições da civilização ocidental.

A rua da cidade oriental, tal como Eça a descreve, é menos "fixa" do que no Ocidente; não há qualquer controle da municipalidade, qualquer plano preestabelecido. Se na Paris idealizada por Haussmann ocorre uma padronização e subordinação do "imóvel" privado à beleza e funcionalidade da via pública, aqui, diferentemente, "as casas que apertam aquela fenda tortuosa, que é a rua, têm uma irregularidade, um imprevisto, um desdém de toda correção (...)" (Eça de Queiroz, 1979: 720). A rua seria, assim, a oposição absoluta do que preconizavam as medidas que já antes de Haussmann caracterizavam o bulevar parisiense, onde a uniformidade e a regularidade são os ideais absolutos da paisagem. Já ao descrever, por exemplo, o café turco ou mesmo bazar, o autor procura atribuir certa ordem, ainda que 1 imitada, ao que parece caótico, à convivência de raças, de culturas, ou à presença de arcaísmos estéticos e econômicos, o que envolve um questionamento da cidade ocidental que vai além da referência à reforma de Haussmann: diz respeito aos caminhos diversos tomados pelas cidades oriental e ocidental desde o Renascimento.

Trata-se, em parte, da identidade, romântica, do Oriente com o passado ocidental. 0 Visconde de Vogué considerava ser mesmo mais instrutivo, para a compreensão da idade média européia, uma visita ao velho Cairo do que a leitura de Michelet... (cf. Berchet, 1984:18) Contudo, pode-se dizer que reviver, sincronicamente, um outro tempo do Ocidente pode significar experiências diversas. No caso de um viajante como Antonin Thivel, espécie de peregrino moderno que, em 1880, escreveu L'Orient, tableau historique et poétique de l'Egypte, tratava-se de uma nostalgia de uma ordem hierárquica e racial. No caso de Eça, diferentemente, a experiência com o tempo sincrônico aproxima-se de uma contestação de um discurso urbanístico que, desde o renascimento, procura fazer da cidade um espaço plenamente controlado, 1 impo, homogeneizado, previsivel (cf. Certeau, 1994).

Trata-se, portanto, de uma experiência específica de evasão, pois até o fim do século XVIII o espaço "sem sentido" da cidade oriental era expressamente rejeitado e, até em Lamartine, o espaço urbano no Oriente não representa para o ocidental nada muito além das suas faltas. Por outro lado, a presença de uma 
fascinação romântica pelo pitoresco das ruas do Cairo, como a que podemos encontrar em Nerval, era ainda excessivamente literária. Diferentemente, Eça coloca seu ol har exótico e nostálgico a meio caminho entre uma visão plenamente encantada e uma fascinação mais refletida, que o leva a certo questionamento da sua cultura de origem.

É verdade que se trata de uma crítica bem limitada, devido à própria concepção que o ocidental possui da temporalidade oriental, sempre passiva exatamente porque trata-se de um passado que não pode deixar de sê-10. Contudo, é possivel dizer que encontramos aqui uma nova imagem do oriente, que expressa novas necessidades e apreensões do ocidental. De forma mais ou menos profunda, as novas experiências do tempo e do espaço são compartilhadas por viajantes posteriores, nos quais encontramos, em descrições da reforma urbana no Cairo (que ocorre a partir da década de 1860), imagens dos equívocos da ocidentalização.

Para Arthur Rhoné, que em 1877 escreve L'Egypte a petites journées a partir de um material reunido entre 1965 e anos seguintes, a parte antiga do Cairo já se transforma em ruîna. Não a ruína modelada pelo tempo mas, de forma semelhante a uma antiga categorização de Chateaubriand, uma ruína fabricada pelos homens, voluntariamente. Rhoné havia conhecido o Cairo em 1864, quando a cidade ainda podia ser definida como o oposto de Paris: nenhuma casa com cinco andares, nenhuma calçada, nenhuma iluminação pública, tudo aquilo que, mais de um século antes, ao tempo das Lettres Persannes, um oriental deveria ambicionar, tudo aquilo que o ocidental considerava como próprio de uma cidade, sinal de progresso, felicidade. Não apenas o Cairo estava ainda "dans toute sa splendeur arabe et musulmane" mas, sobretudo, o tempo longo, secular era ainda o senhor da decadência oriental: "Au pied d'innombrables mosquées de tous les âges, dont quelques-unes mouraient pacifiquement entourées d'un saint respect, couraient des rues sinueuses et abritées, animées par une foule joyeuse et bariolée" (Rhoné, 1910: 2).

Em que pese o topos recorrente em relação ao Oriente, isto é, da ruína e do abandono como um verdadeiro "costume", sua decadência secular não é mais vista tão negativamente, tendo se transformado em uma quase natureza. Daí a descrição, pelo autor, da morte pacífica, tranqüila e sagrada dos monumentos e das mesquitas. Apesar de certa ironia, tudo naquela antiga cidade "combinava" ainda entre si, 


\section{EMTESE}

Belo Horizonte, v. 7, p. I-I I 0, dez. 2003

compondo uma paisagem harmônica, na qual estavam incluídos os homens. A referência pictórica da descrição urbana expressa a harmonia das cores e formas, que se encerrará, para o autor, com o que se definia como alinhamento urbano: alargamento de ruas, supressão dos muxarabis, destruição de impasses, etc. Com efeito, Rhoné percebe que em quinze anos havia se destruído mais do que "um século do tempo passado", tendo ocorrido uma mudança na qualidade do tempo, indistinta da transformação do espaço.

A partir do momento em que as formas do espaço e do tempo ocidentais penetram no Oriente, destruindo referências espaciais e temporais, corre-se o risco, conclui o viajante, de que o Oriente se torne incapaz de alterar a referência de temporalidade que o viajante ocidental traz em sua bagagem. Por isso parece haver, em relação ao Oriente, certo estremecimento no ideal de progresso.

0 discurso da civilização e do progresso europeus aparece, nas narrativas de viagem ao Brasil, de forma bem menos problemática do que nas narrativas ao Oriente.

Quando pensamos em uma imagem estrangeira do Brasil, ela nos vem na forma da palmeira, da floresta, da praia, da natureza isenta de cultura, do caos humano e urbano. A identificação do Brasil com a sua natureza tropical não foi gerada em apenas um século, mas com certeza é no século XIX que ela se afirma como tradição. E, com efeito, nas narrativas de viajantes europeus durante o século XIX a visibilidade e a positividade da natureza serão maiores que as da "cidade". Para Adolphe d'Assier, que viaja ao Brasil na década de 1860, a chegada ao Rio revela um contraste chocante entre a paisagem natural e a urbana:

A peine débarqué, vous vous élancez dans la cidade avec la hâte fiévreuse d'un homme qui ne veut rien perdre du spectacle qu'il a longtemps rêvé. Ici commencent les déceptions: le cadre d'éternelle verdure que vous admiriez avant d'atteindre la ville disparaît tout à coup pour faire place à un soleil de feu. Des rues pleines de nègres et d'effluves ammoniacaux saisissent 1 'œil et l'odorat (...) (ASSIER, 1867: 185).

Por outro lado, esta negação do locus amoenus que é a cidade aparece, por meio de um olhar sobre a cultura marcado pela história natural, pela naturalização 
das produções culturais, ou ainda devido a uma aproximação do tempo social com um tempo da natureza, como um espaço mais próximo da natureza do que da história, se considerarmos que no século XIX a História é em grande parte considerada território de ação consciente e política.

Assim como em uma crônica de Machado de Assis, na qual o viajante estrangeiro no Rio preferia ver a natureza a visitar uma igreja, a exclusão da "ação do homem, a vontade brasileira" (apud. Bastide, 1940) também ocorre, de forma diversa, na busca do pitoresco humano. 0 viajante Charles Ribeyrolles, por exemplo, ao dissertar sobre a permanente ausência ou mesquinhez do monumento na capital brasileira, conclui que "mais vale ir ao mercado admirar as negras quitandeiras a ondular sob os cestos de bananas" (Ribeyrolles, 1941:163). Em que pesem a retórica e a ironia, é digna de nota a recorrência desta imagem, através da qual a paisagem humana adquire o status de monumento.

Dez anos depois Arthur de Gobineau escreve algo semelhante, quando, durante a Semana Santa no Rio, nota a presença de "belas negras com vestidos brancos bordados, braços à mostra, um grande xale drapeando o busto, muitas correntes de ouro e pulseiras, um grande turbante branco e, por cima, o quê? Ninguém no mundo é capaz de adivinhar: um guarda-chuva branco. Elas avançam altaneiras nesses trajes, com o leque na mão" (Apud. Raeders, 1997: 31). Fascinado por este belo espetáculo, Gobineau acha sem graça a monumental paisagem carioca: "Garanti a Suas Majestades que era muito mais curioso e interessante do que todas as vistas que pudesse ter do al to do Corcovado, para onde elas se dignavam querer enviar-me" (Apud. Raeders, 1997: 31).

Em Gobineau, no lugar da já tradicional paisagem natural, o viajante interessa-se pelo homem; mas pelo homem exótico, pela paisagem humana. Em Ribeyrolles, a substituição do monumento, signo da civilização, é feita diretamente por outros signos da cultura ou, em todo caso, da invenção humana: as roupas, as danças, as cores que portam as negras.

A referência ao mundo natural encontra-se, sobretudo, na forma de classificar e categorizar os aspectos visíveis da "paisagem", no caso humana, e de torná-la objeto científico ou estético. Assim, mesmo que os aspectos históricos e 


\section{EMTESE}

Belo Horizonte, v. 7, p. I-I I0, dez. 2003

culturais dessa paisagem sejam levados em consideração, mesmo que se trate de mostrar qualidades, invenções humanas, estas estão subordinadas à natureza, à forma de se olhar a natureza. Não são produções "conscientes", mas sim resultantes de certo acaso, de um tempo longo e involuntário.

Assim, se muitas vezes a natureza enquanto tal, como destaca Ribeyrolles, não está devidamente representada na cidade, uma outra natureza, na forma humana do exotismo e da permanência de costumes arcaicos como a escravidão, domina a cena urbana. A convivência deste quadro a um só tempo urbano e "natural" com imagens de um movimento histórico superficial (que imita as aparências da civilização) e uma memória mais "residual" que voluntária, produz uma visão naturalizada da cidade e seus homens. Ali, a história seria feita quase à sua revelia.

Perante esse domínio da natureza, o choque entre a ação da civilização e a inércia tropical é em geral sem culpa e assim se manterá (ainda que já existam exceções desde o começo do século XIX). Com efeito, o conflito do europeu com respeito à aplicação dos ideais da civilização aparece somente enquanto certa frustração com os equívocos da cópia. Isto é: se a cópia se revelava falha, não havia sinal de destruição - o que ocorre na experiência oriental.

Se é possível dizer que há uma semelhança entre o olhar do viajante europeu sobre o Brasil e sobre o Oriente no que diz respeito às ausências do progresso, ou à sua superficialidade, os efeitos da ocidentalização no Oriente são muito mais brutais, porque as tradições ali são vistas como antigas, profundas, enquanto no Brasil, na cidade brasileira, não haveria uma verdadeira cultura, verdadeira história, verdadeiras tradições. Apesar do peso destas últimas, elas podem ser, como os homens e a paisagem, associadas à natureza. 
RESUMÉ :

Dans un siècle - le XIXème - où l'histoire est identifiée au temps linéaire et progressif, les récits de voyage au Brésil et en Orient sont ponctués par des images d'absence de l'histoire. Toutefois, l'Orient sera identifié surtout au passé, pendant que le Brésil sera identifié à la nature.

MOTS-CLÉS: Orient, récit de voyage, voyageurs, histoire, nature, passé, villes.

\section{REFERÊNCIAS BIBLIOGRÁFICAS}

ASSIER, Adolphe d'. Le Brésil contemporain; races, meurs, institutions, paysage. Paris: Durand et Lauriel, 1867. BASTIDE, Roger. Machado de Assis, paisagista. In: Revista do Brasil, n.29, p.1-14, nov/1940.

CERTEAU, Michel de. A invenção do cotidiano. Petrópolis: Vozes, 1994.

EÇA DE QUEIROZ. O Egito. Notas de viagem. In: Obras de Eça de Queiroz. Porto: Lel10 \& Irmão-Editores, 1979. V.3.

LÉVI-STRAUSS, Claude. Race et histoire. Paris: Denoël, 1990.

MONTESQUIEU. Lettres Persanes. Paris: Gallimard, 1973.

RAEDERS, Georges. O Conde de Gobineau no Brasil. São Paulo: Paz e Terra, 1997.

RHONÉ, Arthur. L'Egypte a petites journées. Le Caire d'autrefois. Nouvelle édition. Paris: Societe generale d'éditions/ Henri Jouve Editeur, 1910.

RIBEYRolles, Charles. Brasil Pitoresco. São Paulo: Livraria Martins, 1941. v.1.

THIVEL, Antonin. L'Orient, tableau historique et poétique de l'Egypte. Paris: E. Dentu, Librairie-Editeur, 1880. 